\title{
Nanomodification of cement-based composites in the technological life cycle
}

\author{
E.M. Chernishov (iD, O.V. Artamonova* iD, G.S. Slavcheva iD \\ Voronezh State Technical University, Voronezh, Russia \\ *Corresponding author: e-mail: ol_artam@rambler.ru
}

\begin{abstract}
The paper reviews the theoretical framework of nanomodification principles of building composites and the conceptual model of the nanomodification from the point of view of the evolutionary model of the solid phase formation depending on the kinetics of heterogeneous processes. According to the route, the main factors of the cement system nanomodifcation were identified for all stages of the technological life cycle. These are associated with the nano-sized particles playing the role of a) structure-forming nuclei, b) substrates for crystallization, c) centers of new formation zoning in the matrix substance of the material, d) nano-reinforcing matrix element. The concepts of the nanomodification and technological tools of the nanomodification of building composites are substantiated. Their hydration kinetics, phase composition, microstructure, rheology and strength characteristics are investigated in order to evaluate the efficiency of the nanomodification principles. It is shown that the use of the nanomodifiers enhances the ductility of cement paste, accelerates cement hydration processes by $9-28$ times, and increases strength by $1.5-2$ times. This will reduce the cost of flow, casting and hardening processes in the technological life cycle of cement-based composites.
\end{abstract}

KEYWORDS: nanomodification, nanoparticles, evolutionary route, technological life cycle, properties of cement-based composites. FOR CITATION: Chernishov E.M., Artamonova O.V., Slavcheva G.S., Nanomodification of cement-based composites in the technological life cycle. Nanotechnologies in Construction. 2020, Vol. 12, no. 3, pp. 130-139. DOI: 10.15828/2075-8545-2020-12-3-130-139.

\section{INTRODUCTION}

A $n$ advanced level of cement-based composite's properties such as High Performance Concrete (HPC), Ultra High Performance Concrete (UHPC), 3D-printable concrete are largely determined by a structural modification of the cementitious matrix through using micro/ nanoparticles and fibers. Nanoparticles (NPs) as additives to cement-based composites have been the focus of recent researches, as it is envisioned that their uniquely high surface area and reactivity can beneficially modify the mechanical and durability properties of cement-based materials [1-4].

In our previous experimental studies, we considered the possibility and efficiency of using 12 additives attributable [6] to three groups based on the size: 1) the group of nano-sized ones - specially synthesized particles $\mathrm{SiO}_{2} \times \mathrm{nH}_{2} \mathrm{O}$, sols of aluminum hydroxide particles and iron hydroxide, montmorillonite, NaX type zeolite, chrysotile nanotubes, fulleroid type carbon nanotubes; 2 ) the group of ultrafine ones - silica fume (waste of ferroalloy production), carbon pipes of the type "Astralen-C", a departure from the combustion of high-energy fuel; 3 ) to the group of micro-disperse ones - natural montmorillonite, tripoli, shungite. These additives were monitored by the effect of their type, dosage, and methods of introduction into the cement-water suspension on the structure formation processes [6, 7]. When varying the dosage of nano-additives from 1 to $0.0001 \%$ of the cement mass, it was shown that its optimal value corresponds to hundredths of a percent. Based on the monitoring, a different measure of the effect of the studied additives was revealed and it was found that the most effective of them can be considered as additive of $\mathrm{SiO}_{2}$ nanoparticles, chrysotile or carbon nanotubes.

The analysis of the literature and our previous results (see, for example, References [6-9]) indicated that the most effective additives for modifying hardening cement paste are those containing inorganic nanoparticles similar in crystal-chemical structure (for example, $\mathrm{SiO}_{2}$ ) and SPs. However, a nano-particulate silica-based modifier is technologically difficult to use, because it should be

(c) Chernishov E.M., Artamonova O.V., Slavcheva G.S., 2020 
uniformly distributed throughout the material. This issue can be resolved if an additive is prepared in an aqueous medium, which is then used as the water of hydration. Note that an SP introduced into a combined additive during synthesis should have two functions: on the one hand, it should stabilize the growth of colloidal silica aggregates, and on the other, it should subsequently help resolve the technical problem of uniformly distributing the combined additive over the cement system during the cement preparation process. We have developed a process for the sol-gel synthesis of a $\mathrm{SiO}_{2}$-based combined additive (CND) in the presence of superplasticizers and investigated the hydration kinetics, phase composition, microstructure, and strength characteristics of modified cementitious materials [10]. The results demonstrated that the combined nano-additives (CND) accelerated hydration processes due to the rapid accumulation of the cementitious substance during the hardening system formation process. The results of a detailed study of modified cement systems were used to optimize the composition of the combined additive.

However, in previous studies, there is no generalized approach to the nanomodifiction of the cement-based composite's structure, based on nano-effects and nanophenomena in the formation of a hardening system within the framework of the technological life cycle of cementbased composites.

In our work, an attempt is made to identify the essence of the mechanisms of nano phenomena to determine the conditions for the effective control of the structure formation of the cementitious matrix as a hardening system. The structure formation of the cementitious matrix is considered during the technological life cycle of cement based composites, including stages of mixing, flow, casting and hardening (Fig. 1).
It is supposed that the rheological behaviour of viscous-plastic cement-based during mixing, flow and casting depends on coagulative contacts in the cementitious matrix, and advanced peculiar properties are determined by converting coagulative contacts to crystal contacts during hydration and hardening.

The first part of the article gives our scientific ideas about evolutionary route of solid substance formation regarding the processes of hydration and hardening of cement systems. According to the evolutionary route, the main factors and criteria of the nano-modifcation of cement-based composites have been identified for all the stages of the technological life cycle. In the second part of the paper, the examples of experimental verification of theoretical approaches to the nano-modification of cement systems are presented.

\section{THEORETICAL FRAMEWORK}

The fixed assets of the «nano tool», implemented in construction materials technologies, include the influence and effect of «top-down» and «bottom-up» nanotechnological approaches [6]. The «nano top-down» approach is based on the use of the phenomenon of changes in the energy state of the structure and, accordingly, the physical and/or physicochemical activity of surface and internal volumes of particles of a solid as they are crushed by mechanical or physical methods.

The effectiveness of the principle is determined not only by the nano-, micro-size of the particles, but also by the measure of the amorphization of their surface volumes. Amorphization is expressed in the «saturation» of volumes with structural defects of the nano-size range. The principle is the basis of the mechanochemical activa-

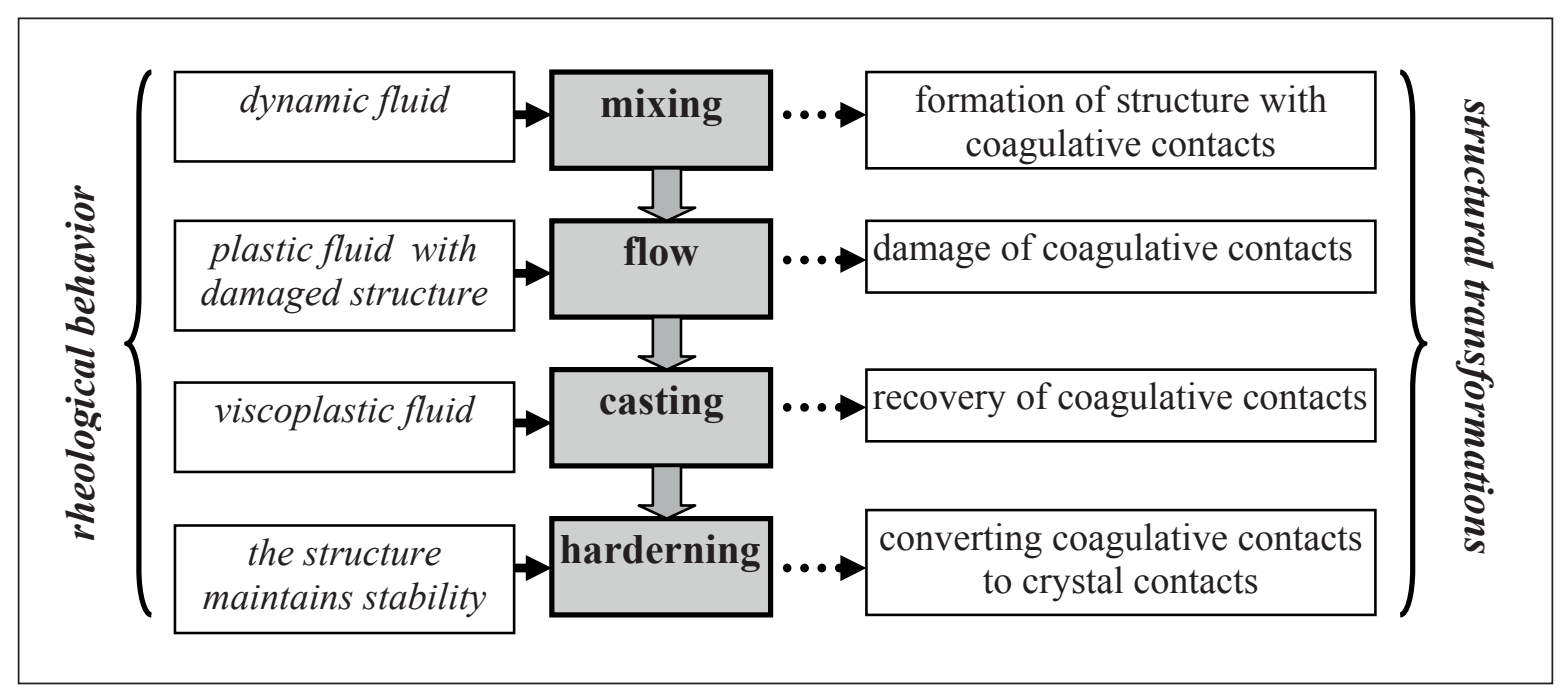

Fig. 1. The technological life cycle of the cement-based composites 
tion of the components of raw mixtures in the technologies of building materials.

The «nano bottom-up» principle is based on the control of condensation phenomena in the evolutionary route of the formation of a solid-phase state of a substance in hydration, hydrothermal-synthesis, thermal synthesis hardening systems. The effectiveness of the principle is determined by the possibilities of effecting the development of stages, transitions, selections in the evolutionary route, and, in general, the kinetics of heterogeneous processes of hydration, colloidation, crystallization in the systems (mixtures) of basic and acidic oxides when developing building materials.
In disclosing and analyzing a general evolutionary model of the formation of a solid, one can follow the interpretations of I.V. Melikhova [11].

In accordance with modern concepts applicable to systems of any composition, the following main stages in the evolution of a substance can be distinguished in the formation of a solid: the nucleation of a solid phase, particle growth, agglomeration, spontaneous transformation in time (Fig. 2). In this case, it is necessary to talk of three evolutionary transitions between the stages and, accordingly, the phenomena of molecular, topological and morphological selections. It is important to emphasize that each stage corresponds to a certain range of sizes of

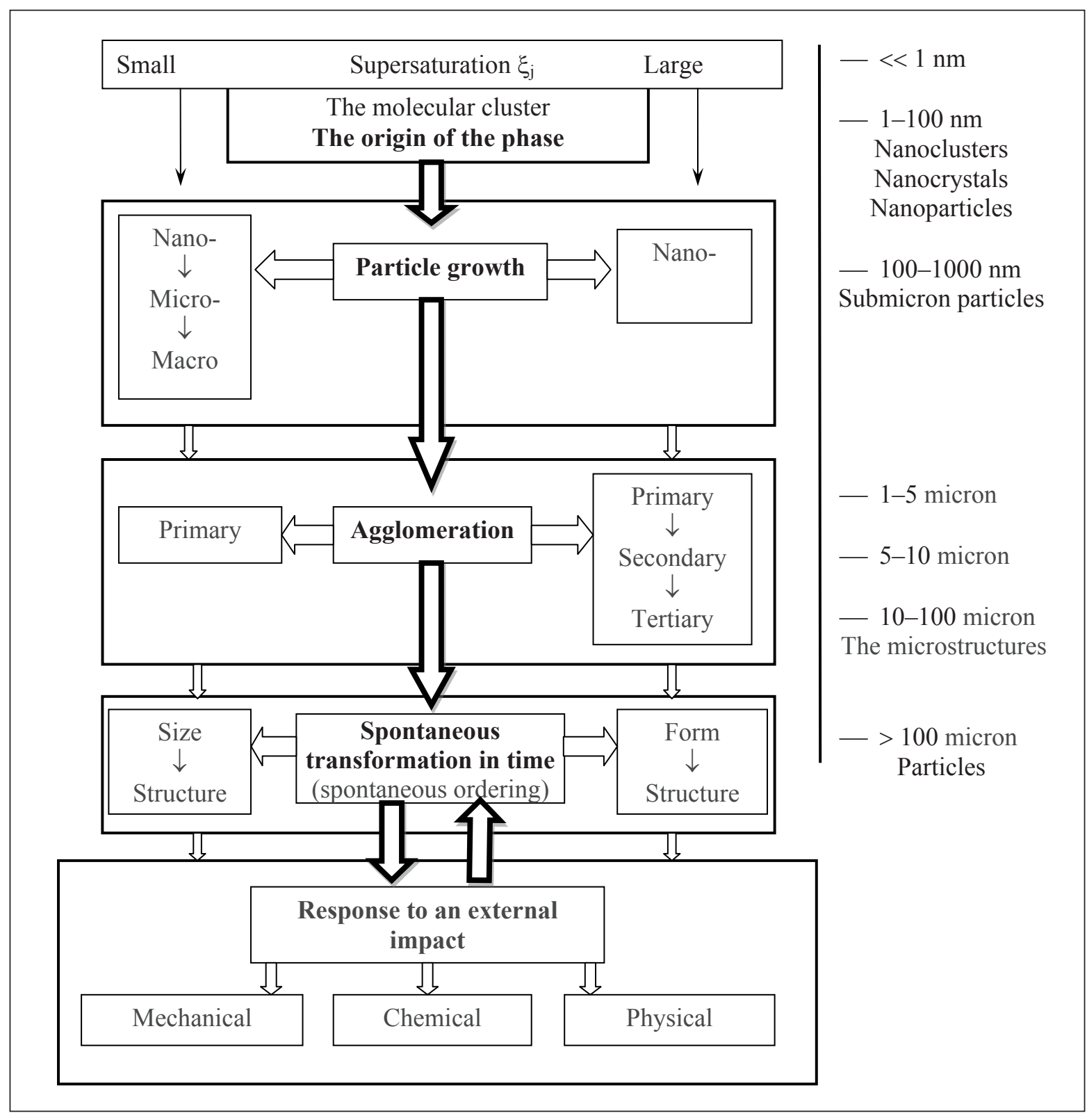

Fig. 2. The evolutionary route of solid substances formation and «dimensional scale» of its structural components 
solid particles based on them. The size scale is shown in Fig. 2. It illustrates dimensional and geometric boundaries and limits. It is clear that we can use the «arsenal of nano» most significantly at the stages of nucleation of the phase and growth of particles.

At other stages, other physicochemical methods of technological impact, affecting the micro and macroscale of the evolutionary process, become priorities. This should be taken into account when developing methods of influence on each of the considered stages and transitions of the evolutionary route. Based on this, a detailed discussion of the determining stages of the evolutionary route and transitions between them should be carried out, bearing in mind the rationale and formation of nanoresources, but not only «nano» in the technology of building materials, if we take into account the problem of modifying the structure on all its scale levels.

Summarizing the analysis of the evolutionary route of the solid state and the related analysis of engineering and technological methods and means of structure nano-modifying, it is possibly reasonable to present a systematics of the main phenomena and driving forces of the structural transitions between the stages of the route, factors controlling these transitions, their mechanisms effects on the hardening system (Table 1). The effects of structure formation control could be observed when the method of introducing nanoscale particles is applied.

These are associated with the nano-sized particles playing the role of a) structure-forming nuclei, b) substrates for crystallization, c) centers of new formation zoning in the matrix substance of the material, d) nanoreinforcing matrix element. In all these cases, the essential point is the lowering of the energy threshold for activating the processes of synthesizing hardening systems and accelerating hardening. Another important point is the spatial geometric modification of the structure, which, as was noted, is its zoning and the corresponding effect on the characteristics of homogeneity-inhomogeneity and, as a result, on the mechanical properties of the material [12]. Finally, one should also keep in mind the effects of disperse reinforcement.

\section{Table 1}

Systematics of structural modification mechanisms at the main transitions of the evolutionary route of solid substance formation

\begin{tabular}{|c|c|c|c|c|c|c|}
\hline $\begin{array}{l}\text { Stage of } \\
\text { the process }\end{array}$ & $\begin{array}{c}\text { Transition } \\
\text { phenomenon }\end{array}$ & Driving force & Control factors & $\begin{array}{l}\text { Control } \\
\text { techniques }\end{array}$ & $\begin{array}{l}\text { Modifying } \\
\text { mechanism }\end{array}$ & Modification result \\
\hline 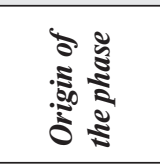 & \multirow{2}{*}{$\begin{array}{l}\text { Molecular } \\
\text { selection }\end{array}$} & \multirow{2}{*}{$\begin{array}{c}\text { Reducing } \\
\text { the chemical } \\
\text { potential } \\
\text { of the system }\end{array}$} & \multirow{2}{*}{$\begin{array}{l}\text { 1) the radius of the } \\
\text { nucleus phase; } \\
\text { 2) the degree of } \\
\text { super-saturation } \\
\text { of the solution } \\
\text { (concentration and } \\
\text { solubility of the } \\
\text { phase-form-ing } \\
\text { substance) }\end{array}$} & \multirow{2}{*}{$\begin{array}{l}\text { 1) methods of } \\
\text { synthesis, de- } \\
\text { pending on the } \\
\text { type of the na- } \\
\text { scent phase; } \\
\text { 2) the introduc- } \\
\text { tion of nano- } \\
\text { sized additives }\end{array}$} & \multirow{2}{*}{$\begin{array}{l}\text { 1) direct physico- } \\
\text { chemical interac- } \\
\text { tion; } \\
\text { 2) the catalytic } \\
\text { role of nanoscale } \\
\text { particles }\end{array}$} & \multirow{2}{*}{$\begin{array}{l}\text { 1) the formation of a } \\
\text { molecular cluster; } \\
\text { 2) a decrease in the } \\
\text { activation energy of } \\
\text { the process; } \\
\text { 3) crystallization cen- } \\
\text { ters of the hardening } \\
\text { structure }\end{array}$} \\
\hline \multirow{2}{*}{ 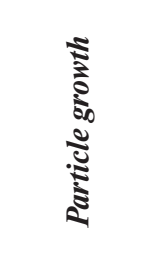 } & & & & & & \\
\hline & & & 1) the type & 1) the introduc- & 1) electro-static & 1) change in thermo- \\
\hline \multirow{2}{*}{ 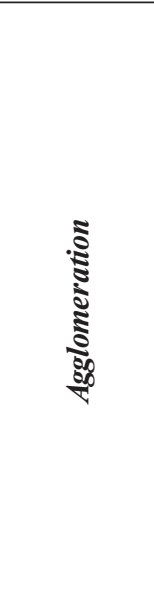 } & $\begin{array}{l}\text { Topological } \\
\text { selection }\end{array}$ & $\begin{array}{l}\text { Reducing } \\
\text { the surface } \\
\text { energy } \\
\text { of the system }\end{array}$ & $\begin{array}{l}\text { and chemical } \\
\text { adsorption; } \\
\text { 2) the degree of } \\
\text { dispersion; } \\
\text { 3) formation of } \\
\text { a fractal grid of } \\
\text { solvent }\end{array}$ & $\begin{array}{l}\text { ers and SP; } \\
\text { 2) the introduc- } \\
\text { tion of nano- } \\
\text { and ultrafine } \\
\text { carbon particles }\end{array}$ & $\begin{array}{l}\text { dispersion of the } \\
\text { system; } \\
\text { 2) changes in the } \\
\text { reaction surface } \\
\text { and system } \\
\text { morphology }\end{array}$ & $\begin{array}{l}\text { ics of the hardening } \\
\text { process; } \\
\text { 2) changes in the } \\
\text { composition, struc- } \\
\text { ture and properties of } \\
\text { solids }\end{array}$ \\
\hline & $\begin{array}{l}\text { Morphological } \\
\text { selection }\end{array}$ & $\begin{array}{l}\text { Reducing } \\
\text { the total } \\
\text { energy } \\
\text { of the system }\end{array}$ & $\begin{array}{l}\text { 1) the change in } \\
\text { the inter-granular } \\
\text { surface of the sys- } \\
\text { tem; } \\
\text { 2) the formation of } \\
\text { additional bound- } \\
\text { aries }\end{array}$ & $\begin{array}{l}\text { heat treatment, } \\
\text { pressing, the } \\
\text { introduction } \\
\text { of additives of } \\
\text { micro-particles }\end{array}$ & $\begin{array}{l}\text { 1) zoning struc- } \\
\text { ture of hardening; } \\
\text { 2) implementa- } \\
\text { tion of topo- } \\
\text { chemical memory } \\
\text { additives }\end{array}$ & $\begin{array}{l}\text { 1) an increase in the } \\
\text { area of intergranular } \\
\text { contacts; } \\
\text { 2) dispersed reinforce- } \\
\text { ment of the structure; } \\
\text { 3) formation of or- } \\
\text { dered hardening } \\
\text { structures with dense } \\
\text { packing of crystals }\end{array}$ \\
\hline
\end{tabular}




\section{EXPERIMENTAL STUDY}

This part of the article presents research results illustrating the implementation of the nano-principle «bottom-up» in the structure formation process and properties of cement systems. The results demonstrate the influence of combined nano-additives on the plasticity, kinetics of hydration and hardening of cement paste, structure and strength of hardened cement paste.

\subsection{Materials and methods}

Three types of cement pastes as matrix of cement based composites were studied:

$\mathrm{C}+\mathrm{W}-$ reference cement system without additives; $\mathrm{C}+\mathrm{W}+\mathrm{CND}-$ cement system with the complex additive of $\mathrm{SiO}_{2}$ nanoparticles in combination with a plasticizer (additive CND), synthesized according to the original author's method; $\mathrm{C}+\mathrm{W}+\mathrm{CNT}-$ cement system with addition of carbon nanotubes of the fulle-roid type of the brand «Nanocyl-7000», treated with ultrasound (additive CNT). Portland cement CEM I 42.5 (EN 1971:2011) plasticizer of Sika trademark based on polycarboxylic ethers, manufacturing water and these nano-additives with a different dosage were used in the experiments for the production of cement paste with a $\mathrm{W} / \mathrm{C}=0.33$. Hydration kinetics, phase composition, morphology of the structure, plastisity and strength kinetics have been investigated for the three types of cement pastes (Table 2).

Studies of the parameters of the kinetics of the cement hydration process were carried out under thermostatic conditions at temperatures of $0 ; 20 ; 40 ; 60^{\circ} \mathrm{C}$ (respectively, $273 ; 293 ; 313 ; 333 \mathrm{~K}$ ), with the duration of the process of 1, 3, 7, 12 hours; 1, 3, 7, 14, 28 days.

The morphology of the structure of the hardened cement paste was examined on a JEOL JSM-7001F scan- ning electron microscope. The phase composition of the reference and nano-modified cement paste was monitored by the X-ray method (CuK $\alpha$ radiation, $\lambda=1.541788 \AA$, ARL X'TRA diffractometer). The processing of diffractometric data was carried out automatically using the PDWin 4.0 computer program. The hydration degree $D_{h}$ $\left(\mathrm{C}_{3} \mathrm{~S}\right)$ was calculated [6] by the formula

$$
\mathrm{D}_{\mathrm{h}}\left(\mathrm{C}_{3} \mathrm{~S}\right)=\left(1-\mathrm{I}_{\mathrm{m}} / \mathrm{I}_{0}\right) \cdot 100 \%,
$$

$\mathrm{I}_{\mathrm{m}}-$ the diffraction intensity of $3 \mathrm{CaO} \cdot \mathrm{SiO}_{2}\left(\mathrm{C}_{3} \mathrm{~S}\right)$ $(\mathrm{d}=2.75 \AA$ ) phase for hardening cement paste samples; $\mathrm{I}_{0}-$ the diffraction intensity of $3 \mathrm{CaO} \cdot \mathrm{SiO}_{2}\left(\mathrm{C}_{3} \mathrm{~S}\right)(\mathrm{d}=$ $2.75 \AA$ ) for cement.

To evaluate the plasticity of the cement pastes during flow and casting the squeezing test with the constant plate speed $(\mathrm{v}=5 \mathrm{~mm} / \mathrm{sec})$ was used in accordance with the methodology developed in the works of N. Roussel [13]. The test was used as the estimation criterion of the behavior of the system in the flow and casting process. Cylindrical samples of fresh cement paste with radius $\mathrm{R}$ equal to their height $\mathrm{h} 0=25 \mathrm{~mm}$ were used for the implementation of the experiment. For the squeezing test, a sample was put between two smooth plates, diameter of which corresponded to the size of the sample and was loaded into a universal floor hydraulic testing system «INSTRON Sates 1500 HDS». The curves «compression force $\mathrm{N}-$ displacement $\Delta »$ obtained during the experiments were interpreted as influence curves of reduced compression load $\mathrm{F}^{*}$ from the relative change of the height of the sample.

$$
\mathrm{F}_{\mathrm{i}}^{*}=\mathrm{Ph}_{\mathrm{i}} / \pi \mathrm{R}^{2}
$$

where, $\mathrm{h}_{\mathrm{i}}=\left(\mathrm{h}_{0}-\Delta\right), \mathrm{h} 0$ is the initial height of the sample, $\Delta$ is the transfer in the i point of time, value $\mathrm{R}$ was

\section{Table 2}

Test matrix

\begin{tabular}{|l|c|c|c|c|c|}
\hline \multirow{2}{*}{\multicolumn{1}{c|}{ Variables }} & \multicolumn{3}{c|}{ Specimen ID } \\
\cline { 2 - 6 } & C+W & \multicolumn{2}{c|}{ C+W+CND } & \multicolumn{2}{c|}{ C+W+CNT } \\
\hline $\begin{array}{l}\text { Dosage of nano-additives, } \\
\text { mass/mass cement (\%) }\end{array}$ & 0 & 0.01 & 1 & 0.01 & 1 \\
\hline Plasticizer, mass/mass cement (\%) & 0 & 0.2 & 0.2 & 0 & 0 \\
\hline Morphology of the structure & + & + & - & + & - \\
\hline Phase composition & + & + & + & + & + \\
\hline Cement hydration degree & + & + & - & + & - \\
\hline Kinetic parameters of hydration process & + & + & - & + & - \\
\hline Plasticity & + & + & - & - & - \\
\hline Compressive strength & + & + & + & + & + \\
\hline
\end{tabular}


taken as constant and equal to the radius of the sample at the beginning of the experiment.

According to the results of the analysis of the received experimental curves for the studied systems' values $\mathrm{K}_{\mathrm{i}}$, called plastic yield value by N. Roussel [13], were calculated at the first inflection point of the rheological curve $\mathrm{F}^{*}=f\left(\mathrm{~h}_{\mathrm{i}} / \mathrm{R}\right)$ :

$$
\mathrm{K}_{\mathrm{i}}\left(\mathrm{h}_{\mathrm{i}} / \mathrm{R}\right)=\sqrt{3} \mathrm{~F}^{*} / 2 .
$$

The compressive strength of the hardened cement paste was determined after 1, 3, 7, 14, 28 days under normal temperature and humidity conditions $\left(\mathrm{t}=20^{\circ} \mathrm{C}\right.$, $\mathrm{RH}=95 \pm 5 \%$ ); tests of samples - cubes with a size of $5 \times 5 \times 5 \mathrm{~cm}$ were conducted on an INSTRON Sates 1500 HDS test system; to ensure the statistical reliability of the results of physical and mechanical tests, the number of samples in the series ranged from 9 to 12 . It was determined that the intra-serial coefficient of variability of the results of the strength assessment did not exceed $3-5 \%$.

\subsection{Results and discussions}

\subsubsection{Processes of hydration and structure formation of cement systems}

The energy efficiency of the nano-modification is characterized by our results on changes in speed, temperature coefficient of speed, effective activation energy of the process of cement hydration under the influence of factors of the introduction of nano-additives and changes in temperature conditions, presented in [6]. The generalization of the experimental data shows that in systems with the nano-modifying additives, the cement hydration process is substantially accelerated: by the daily duration of hardening at $20^{\circ} \mathrm{C}(293 \mathrm{~K})$, the degree of hydration reaches at least $70-75 \%$. Such a result for the control «additive-free» system is recorded only by 28 th day. Thus, in this example, the hydration is accelerated by criterion by almost 30 times.

The effect of the accelerating action of additives is valid for all variants of the composition and temperature conditions of hydration, differing, however, in the magnitude and timing of the achieving the limiting values of the hydration degree. For the variants of low temperatures $\left(0^{\circ} \mathrm{C} ; 273 \mathrm{~K}\right)$, the hydration degree of $70-75 \%$ is reached by $7^{\text {th }}$ day, if the additive of pressure coefficient is used, and by $14^{\text {th }}$ day, if the additive of CNT is used. At the same time, in the «additive-free» system, such a hydration degree is not achieved at all. By the $28^{\text {th }}$ day, it makes only $50 \%$ of the possible maximum value. For higher temperatures $\left(40-60^{\circ} \mathrm{C} ; 303-333 \mathrm{~K}\right)$, in systems with the considered nano-additives CND, the degree of hydration already reaches $80-85 \%$ by $1^{\text {st }}$ hour of the hardening; by $7^{\text {th }}$ hour it is $90 \%$, and by the 1 st day up to $95 \%$. Based on this data, it can be concluded that, firstly, in the presence of nano-additives, the main part of the evolutionary route of cement hydration takes place almost within the first hour, and secondly, that the hydration of cement can be completed within the first day.

The effects of such acceleration of hydration are explained by the achieved decrease in the effective activation energy of the process under the conditions of the nano-modification. The effective activation energy required for the process «start» decreases 2.3-2.8 times as compared with the control «additive-free» system. It is worth emphasizing that the experimentally obtained the lowest EEA value $(61.7 \mathrm{~kJ} / \mathrm{mol})$ corresponds to the use of a complex modifying additive based on nano-sized $\mathrm{SiO}_{2}$ particles in combination with a superplasticizer [6]. This is explained by the fact that, unlike carbon nanotubes, $\mathrm{SiO}_{2}$ nanoparticles are related to the mineral phases of hydration products with a crystal chemical structure that facilitates the formation of molecular clusters and nuclei on $\mathrm{SiO}_{2}$ nanoparticles as active crystallization centers. We draw attention here to the fact that the accelerating role of the additive takes place, despite the fact that the surfactant present in the complex additive slows down the hydration processes. The introduction of CND and CNT nano-additives has a significant effect on the chemical, mineralogical composition and morphology of the hydration products.

According to the X-ray analysis data (Fig. 3-4) for the $\mathrm{C}+\mathrm{W}$ reference system, it was found that the hydrated compounds of this system are predominantly highly basic calcium hydrosilicates $\left(2 \mathrm{CaO} \cdot \mathrm{SiO}_{2} \cdot 0.5 \mathrm{H}_{2} \mathrm{O}\right.$, $\left.2 \mathrm{CaO} \cdot \mathrm{SiO}_{2} \cdot \mathrm{H}_{2} \mathrm{O}\right)$, portlandite $\left(\mathrm{Ca}(\mathrm{OH})_{2}\right)$, the quontity of which increases with time. In contrast to the $\mathrm{C}+\mathrm{W}$ system, in the nanomodified $\mathrm{C}+\mathrm{W}+\mathrm{CND}$ system, the phases of tobermorite (present throughout the entire curing time), the low-basic calcium hydrosilicates of the composition $\left(\mathrm{CaO} \cdot \mathrm{SiO}_{2} \cdot \mathrm{H}_{2} \mathrm{O}\right)$ are predominantly registered already on the first day, the number of the phases increases with increasing curing time. On the first day (Fig. 3), the dominant phases in the $\mathrm{C}+\mathrm{W}+\mathrm{CNT}$ system are highly basic calcium hydrosilicates $3\left(2 \mathrm{CaO} \cdot \mathrm{SiO}_{2}\right) \cdot 2 \mathrm{H}_{2} \mathrm{O}$ and $2 \mathrm{CaO} \cdot \mathrm{SiO}_{2} \cdot \mathrm{H}_{2} \mathrm{O}$. By the 28th day of curing (Fig. 3) in the $\mathrm{C}+\mathrm{W}+\mathrm{CND}$ system, the dominant phase is low-basic calcium hydrosilicate $(\mathrm{CaO}) x \cdot \mathrm{SiO} 2 \cdot n \mathrm{H}_{2} \mathrm{O}$, which is also confirmed by scanning electron microscopy (Fig. 4). Obviously, this is due to the introduction of nano-sized particles of $\mathrm{SiO}_{2}$ into the system, which are capable of a chemical interaction with clinker minerals of cement and a decrease in the basicity of the resulting hydrosilicate phases.

In the $\mathrm{C}+\mathrm{W}+\mathrm{CNT}$ system, there is a decrease in the number of highly basic calcium hydrosilicates and an increase in low-basic calcium hydrosilicates. In this case, the ettringite phase $\left(\mathrm{C}_{3} \mathrm{~A} \cdot 3 \mathrm{CaSO}_{4} \cdot 32 \mathrm{H}_{2} \mathrm{O}\right)$ is registered. 


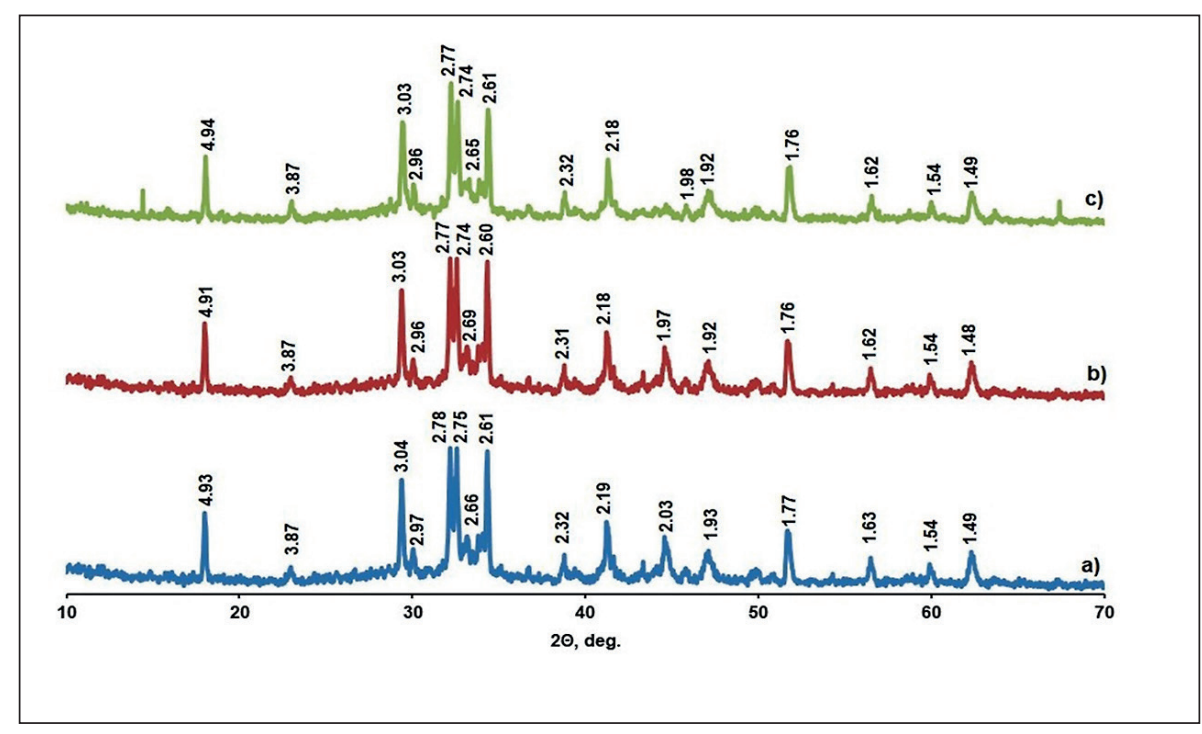

Fig. 3. X-ray diffraction patterns for a nano-modified cement system of one-day curing: a) without addictives; b) modified by $\mathrm{CND}$; c) modified by $\mathrm{CNT}$. $3 \mathrm{CaO} \cdot \mathrm{SiO}_{2}(\mathrm{~d}=3.02 ; 2.75 ; 2.61 ; 2.18 ; 1.76 ; 1.48) ; 2 \mathrm{CaO} \cdot \mathrm{SiO}_{2}(\mathrm{~d}=3.80 ; 3.01 ; 2.74 ; 1.80 ; 1.63)$; $\mathrm{Ca}(\mathrm{OH})_{2}(\mathrm{~d}=4.93 ; 3.11 ; 2.63 ; 1.93 ; 1.79 ; 1.69) ; 2 \mathrm{CaO} \cdot \mathrm{SiO}_{2} \cdot \mathrm{H}_{2} \mathrm{O}(\mathrm{d}=4.77 ; 3.01 ; 2.92 ; 2.37 ; 2.25 ; 1,96)$; $x \mathrm{CaO} \cdot \mathrm{SiO}_{2} \cdot z \mathrm{H}_{2} \mathrm{O}(\mathrm{d}=3.06 ; 2.97 ; 2.80 ; 1.83 ; 1.67) ; 2 \mathrm{CaO} \cdot \mathrm{SiO}_{2} \cdot 0.5 \mathrm{H}_{2} \mathrm{O}(\mathrm{d}=2.99 ; 2.77 ; 2.67 ; 2.58 ; 1.80)$

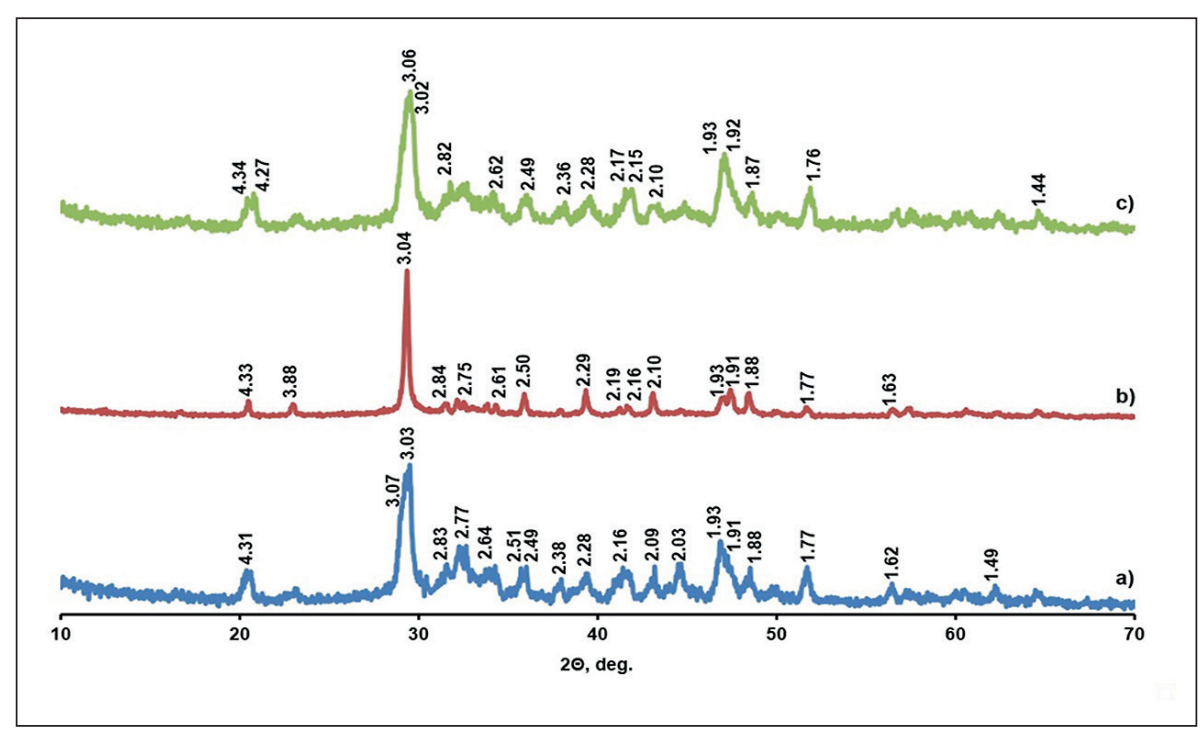

Fig. 4. X-ray diffraction patterns for a nanomodified cement system of 28-day curing: a) without addictives; b) modified by CND; c) modified by CNT.

$3 \mathrm{CaO} \cdot \mathrm{SiO}_{2}(\mathrm{~d}=3.02 ; 2.75 ; 2.61 ; 2.18 ; 1.76 ; 1.48) ; 2 \mathrm{CaO} \cdot \mathrm{SiO}_{2}(\mathrm{~d}=3.80 ; 3.01 ; 2.74 ; 1.80 ; 1.63)$;

$\mathrm{Ca}(\mathrm{OH})_{2}(\mathrm{~d}=4.93 ; 3.11 ; 2.63 ; 1.93 ; 1.79 ; 1.69) ; 2 \mathrm{CaO} \cdot \mathrm{SiO}_{2} \cdot \mathrm{H}_{2} \mathrm{O}(\mathrm{d}=4.77 ; 3.01 ; 2.92 ; 2.37 ; 2.25 ; 1,96)$; $x \mathrm{CaO} \cdot \mathrm{SiO}_{2} \cdot z \mathrm{H}_{2} \mathrm{O}(\mathrm{d}=3.06 ; 2.97 ; 2.80 ; 1.83 ; 1.67) ; 2 \mathrm{CaO} \cdot \mathrm{SiO}_{2} \cdot 0.5 \mathrm{H}_{2} \mathrm{O}(\mathrm{d}=2.99 ; 2.77 ; 2.67 ; 2.58 ; 1.80)$

According to the scanning electron microscopy (SEM), the microstructure of the cementitious matrix is represented by a typical amorphous $\mathrm{C}-\mathrm{S}-\mathrm{H}$-gel, mainly representing poorly crystallized grains of irregular round shape (Fig. 5).
In this case, the particle size of the hydration products and the pores of the particles of unmodified and modified hardened cement pastes differ significantly. The structure of the hardened cement paste without nanomodifiers (Fig. 5 a) is heterogeneous, characterized by the presence 


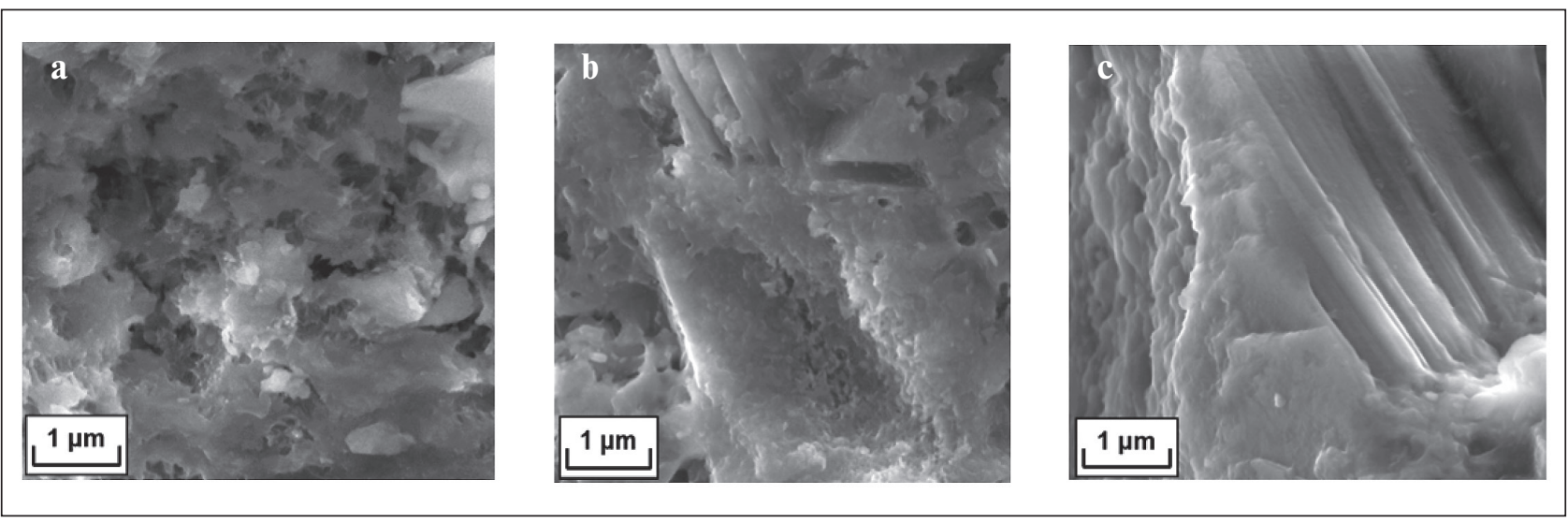

Fig. 5. Hardened cement paste micrographs (hardening time 28 days, SEM): a - without addictives; b - modified by CND; $\mathrm{c}$ - modified by CNT

of larger pores and aggregates of particles, residual grains of a non-hydrated cement clinker. For the nano-modified hardened cement paste, the size of the crystallites formed, the pores of the $\mathrm{C}-\mathrm{S}-\mathrm{H}$-gel, is significantly smaller than in the reference unmodified system (Fig. 5 b, c). In these systems, very small aggregates of crystallites of calcium hydrosilicates predominate; practically no residual grains of the cement clinker are observed. In the modified CNT structure of the hardened cement paste (Fig. $5 \mathrm{c}$ ), the presence of fibrous and plate crystalline aggregates is also noted.

As a result, the structure of the cement stone with CND and CNT is more dense and homogeneous, with a large number of contacts between the particles of the hydration products. We found out that introducing nanoparticles into cement systems accelerates cement hydration processes for the $\mathrm{C}+\mathrm{W}+\mathrm{CND}$ system by 28 times, and for the $\mathrm{C}+\mathrm{W}+\mathrm{CNT}$ system by 9 times. In the modification of CND cement systems, this is due to their catalytic role and the possibility of direct participation in the heterogeneous processes of phase formation of the hydrated compounds. For CNT, this is associated with an additional structuring of mixing water. On the other hand, CNT are nano-reinforcing elements, and as a result, they can significantly zonize the space of the crystallization structure of the hydration products.

Our experimental data confirm the effective development of the cement hydration process provided that the nano-modification determines the optimal combination of the kinetic and diffuses the component of the structure formation process [21]. The kinetic component controls the evolutionary route of the solid formation during the hydration of cement as far as it is possible to realize all the phenomena (stages, transitions, etc.) of the nucleation of particles of the new phase and their development. The diffusion component is acting as an opposed to the kinetic that controls the dynamics of the evolutionary route phenomena. With the optimal combination of these types of the control, it is possible to ensure the minimization of the energy intensity and the duration of the hardening process, which is essential for reducing energy costs and the duration of hardening processes in the technological life cycle of cement-based composites.

\subsubsection{Properties of cement systems}

We found out from (Fig. 6) that with the introduction of CND, the load value and, correspondingly, the plastic yield value $\mathrm{K}_{\mathrm{i}}$. decreased by 2 times, which are necessary for the transition of systems with the same concentration of the dispersed phase (W/C = const) from the state of stability («placing phase» according to N. Roussel [13]) to the state of viscoplastic yeld («perfect plastic response phase» [29]). For cement paste $\mathrm{C}+\mathrm{W}$ plastic yield value $\mathrm{K}_{\mathrm{i} .}=1.65 \mathrm{kPa}$, for $\mathrm{C}+\mathrm{W}+\mathrm{CND}-\mathrm{K}_{\mathrm{i}}=0.84 \mathrm{kPa}$.

The effect of CND is associated with the synergistic effect of the plasticizer and $\mathrm{SiO}_{2}$ nanoparticles. The ductility of the cement paste is determined by the quantity and strength of coagulation contacts. The introduction of a plasticizer into a «cement+water» dispersed system affects the surface phenomena at the phase boundary and molecular interactions between cement particles.

When a cement paste structure is formed in the presence of a plasticizer, a monomolecular plasticizer layer is formed on the surface of the cement particles. As a result, the level of the free interfacial energy at the phase boundary decreases the particles decreases. $\mathrm{SiO}_{2}$ nanoparticles contribute to the intensification of the processes of dissolution and hydrolysis of clinker minerals, the increase the ionic strength of the solution, which contributes to the destruction and reduction of the viscosity of the dispersion medium. Thus, with the introduction of CND, the ductility of the cement paste increases and its yield during mechanical stresses is facilitated, which is essential for 


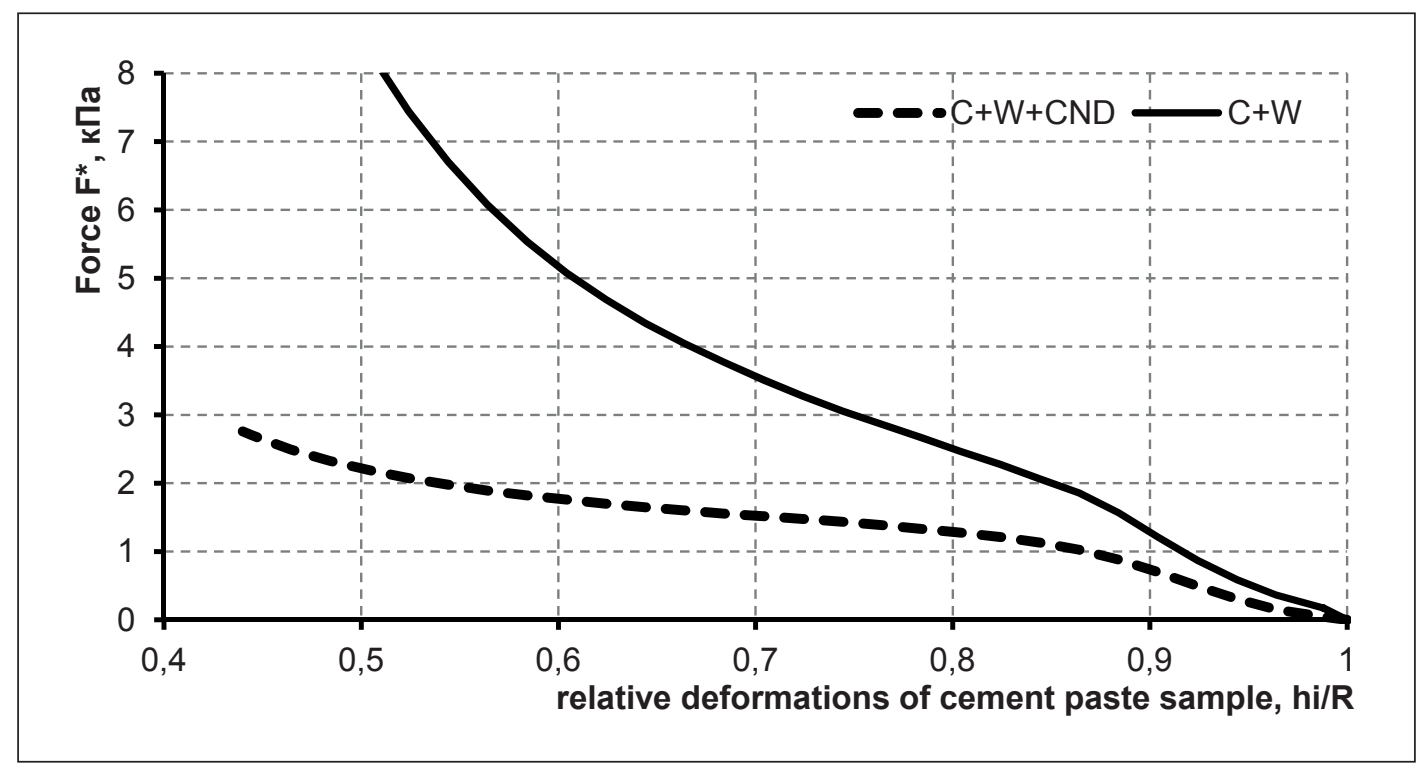

Fig. 6. Tested cement pastes rheological curves $\mathbf{F}^{*}\left(\mathbf{h}_{\mathbf{i}} / \mathbf{R}\right)$

the processes of flow and casting in the technological life cycle of cement-based composites.

In the course of the experiments, when assessing the effect of the nano-modification of the structure on the strength, the above two additives in dosages of $0.01 \%$ and $1 \%$ by mass of the cement were studied [6]. In the case of the use of the complex additive of nanoparticles $\mathrm{SiO}_{2}$ in combination with a superplasticizer (CND), close to the limiting strength values are achieved for compositions with different dosages by the $3^{\text {rd }}$ day of hardening.

The use of CND allows us to provide $70 \%$ of the strength of the values achieved for 28 days, for 1 day. For the option of dosing an additive of $0.01 \%$, an increase in the limiting values of strength up to $90 \mathrm{MPa}$ against $50 \mathrm{MPa}$ in the control «additive-free» system is noted. Such a difference is explained by the modifying effect of the additive on the dispersed and morphological composition of the hydration products, which acquire a nanodispersed and cryptocrystalline state. This is precisely in accordance with the well-known theory of «fine grain» of Rebinder P.A. and the pattern of Hall-Petch and determines the higher resistance to the destruction of the modified structure.

A similar situation occurs with the addition of carbon nanotubes at a dosage of $0.01 \%$. However, the kinetics of strength in this variant of a nano-modification is noticeably different in that in the early stages of hardening, the curing is slower: achieving $70 \%$ of strength of its values at the age of 28 days is provided in this variant for 7 days, and for 1 day cement paste gains only $20 \%$. Another difference concerns the ultimate strength value, which is $80 \mathrm{MPa}$. Based on this data, it can be observed that the introduction of an additive into carbon nanotubes is less effective in comparison with the addition of nanoscale particles of $\mathrm{SiO}_{2}$, and above all in terms of the kinetic parameters of hardening strength.

Based on the results of the experiments, we should specifically dwell on the question of the strength kinetics for the variants with the dosage of additives of $1 \%$ by weight of the cement. With this dosage, an accelerated increase in strength in the initial (1-3 days) hardening periods is also noted. However, no increase in strength is noted in the subsequent periods and it remains at 35$40 \mathrm{MPa}$, which is lower than the values for the control «additive-free» composition. It can be assumed that, at an elevated dosage, the so-called «poisoning» of the system occurs when excessively accelerated hydration of cement and crystallization of new hydration products leads to the development of self-destructive crystallization pressure.

Thus, it was shown that the effect of a nano-modification of cement paste in relation to strength is that it hardens faster in the early stages of the structure formation and becomes more durable when the curing process is completed. This is the basis for a reduction in overall terms of hardening and refusal of heat treatment of cement based composites in the technological life cycle.

\section{CONCLUSIONS}

We experimentally confirmed the nano-modification effects associated with the catalytic role of nanoparticles in cement hydration processes, with a change in the morphology of hydration products, with zoning and clustering of the hardened cement paste microstructure. As a result, the introduction of various types of nanoadditives into cement systems contributes to the acceleration 
of cement hydration processes by 9-28 times, and the increase in strength by 1.5-2 times. At the same time, with the introduction of complex nano-modifiers based on $\mathrm{SiO}_{2}$ nanoparticles and superplasticizer, the ductility of the cement paste increases and its flow during me- chanical stresses is facilitated. All the established effects of the nano-modification are essential for facilitating the processes of flow and casting, reducing energy costs and the duration of hardening processes in the technological life-cycle of cement based composites.

\section{REFERENCES}

1. Sanchez F., Sobolev K. Nanotechnology in concrete - A review. Construction and Building Materials. 2010. V. 24. Pp. 20602071. DOI: 10.1016/j.conbuildmat.2010.03.014.

2. Reches Y. Nanoparticles as concrete additives: Review and perspectives. Construction and Building Materials. 2018. V. 175. Pp. 483-495. DOI: 10.1016/j.conbuildmat.2018.04.214.

3. Paul S. C., Rooyen A. S., Gideon P.A.G. van Zijl et al. Properties of cement - based composites using nanoparticles: A comprehensive review. Construction and Building Materials. 2018. V. 189. Pp. 1019-1034. DOI: 10.1016/j.conbuildmat.2018.09.062.

4. Norhasri M.S., Hamidah M.S., Fadzil A.M. Applications of using nano material in concrete: A review. Construction and Building Materials. 2017. V. 133. Pp. 91-97. DOI: 10.1016/j.conbuildmat.2016.12.005.

5. Rai S., Tiwari S. Nano Silica in Cement Hydration. Materials Today. 2018. V. 5. Pp. 9196-9202. DOI: 10.1016/j.matpr.2017.10.044.

6. Chernyshov E.M., Artamonova O.V., Slavcheva G.S. Concepts and bases of technology nanomodification of the structures of building composites. Part 3: effective nano-modification of cement hardening systems and hardened cement paste structure (criteria and conditions). Construction Materials. 2015. № 10. Pp. 54-64. DOI: 10.31659/0585-430X-2015-730-10-54-63. (In Russian).

7. Chernyshov E.M., Artamonova O.V., Slavcheva G.S. Nanomodification of systems of hardening in the structure of construction composites. Voronezh: Scientific book, 2016. (In Russian).

8. Artamonova O.V., Slavcheva G.S., Chernyshov E.M. Effectiveness of Combined Nanoadditives for Cement Systems. Inorganic Materials. 2017. V. 53. Pp. 1080-1085. DOI: 10.1134/S0020168517100028.

9. Artamonova O.V., Slavcheva G.S., Shvedova M.A. Effectiveness of nanotubular additives in the modification of cement systems. Inorganic Materials. 2020. V. 56. Pp. 105-110. DOI: 10.1134/S0020168520010021.

10. Artamonova O.V. Synthesis of nanomodifying additives for construction composites technology. Voronezh: VGASU, 2016. (In Russian).

11. Melikhov I.V. Physical and chemical evolution of the solid. Moscow: BINOM, A laboratory of Knowledge, 2009. (In Russian).

12. Bullard J., Livingston J., et al. Mechanisms of cement hydration. Cement and Concrete Research. 2011. V. 41. Pp. $1208-1223$. DOI: 10.1016/j.cemconres.2010.09.011.

13. Toutou Z., Roussel N., Lanos C. The squeezing test: A tool to identify firm cement-based material's rheological behaviour and evaluate their extrusion ability. Cement and Concrete Research. 2005. V. 35. Pp. 1891-1899. DOI: 10.1016/j.cemconres.2004.09.007.

\section{INFORMATION ABOUT THE AUTHORS}

Evgeniy M. Chernishov, Doctor of Engineering, Prof., Director of the Research Institute, Academy of Development of the Building Complex, Voronezh State Technical University, Acad RAASN, Voronezh, Russia, ORCID: https://orcid.org/0000-0002-0129-6363, e-mail: chem@vgasu.vrn.ru

Olga V. Artamonova, Doctor of Engineering, Prof. Department of Chemistry and Chemical Technology of Materials, Voronezh State Technical University, Voronezh, Russia, ORCID: https://orcid.org/0000-0001-9157-527X, e-mail: ol_artam@rambler.ru

Galina S. Slavcheva, Doctor of Engineering, Prof. Department of Technology of Building Materials, Products and Structures, Voronezh State Technical University, Voronezh, Russia, ORCID: https://orcid.org/0000-0001-8800-265,

e-mail: gslavcheva@yandex.ru

\section{Author declare the absence of any competing interests.}

Received: 21.04.2020.

Revised: 06.06.2020.

Accepted: 09.06.2020. 